\title{
Integrated Water Resources Management as a System Approach for Water Security: Evidence from the Awash River Basin of Ethiopia
}

\begin{abstract}
Reta Hailu*, Degefa Tolossa ${ }^{\dagger}$ and Getnet Alemu ${ }^{\ddagger}$
Abstract

Integrated Water Resources Management (IWRM) is one of the systems thinking approaches that emerged in the 1990s to achieve water security. Ever since, it has been applied in various countries and contexts. However, the implementation of the IWRM is contested. There is paucity of literature and guidelines as to how the concept can be operationalized. In Ethiopia, there is no evidence that IWRM is successfully instituted. The study generated data from household and expert surveys, in-depth interviews, focused group discussions, observations, workshops, and secondary sources. We found that pragmatic water resources management through system approach helps to resolve the problem of fragmentations among various actors, sectors, interest, and priorities. It also enables the operationalization of IWRM as a system approach to secure water resources through strengthening of the interactions of various systems, subsystems, and the elements within the entire basin system. In addition, it is important to facilitate institutional environments such as overcoming financial constraints, considering the scarcity value of water resources and equity issues, as well as ensuring progressiveness of water institutions to emerging circumstances. To this end, strengthening water resources information systems, recognizing and balancing water as economic and public goods, creating awareness among key stakeholders, encouraging the engagement of private sectors in water resources development and management should be considered as mediums of realizing IWRM.
\end{abstract}

Keywords: IWRM; system thinking; water security; Awash basin; Ethiopia DOI: https://dx.doi.org/10.4314/ejossah.v14i1.3

\footnotetext{
*Assistant Professor, School of Environment, Gender, and Development Studies, Hawassa University, email: bretab.8@gmail.com, Tel:+251911389737

${ }^{\dagger}$ Corresponding Author: Associate Professor, College of Development Studies, Addis Ababa University, email: degefatd@gmail.com, Tel: +251911899660

${ }^{\ddagger}$ Associate Professor, College of Development Studies, Addis Ababa University, email: galemu2001@gmail.com, Tel: +251911529796
}

This work is licensed to the publisher under the Creative Commons Attribution-NonCommercialNoDerivs License. 
Reta Hailu, Degefa Tolossa \& Getnet Alemu

\section{Introduction}

Water security is systemic and complex that needs to be analyzed using systems thinking approach. In systems thinking, the whole is greater than the sum of its parts because a system is dynamic and not simply determined by the actions of an enclave sector (Long, 2001). It is a pathway of thinking, which seeks to detect and comprehend the multitude of problems, their interplays, and interdependencies to solve them. Thus, a system thinking allows thinkers to grasp the uncertainty facing water security (Liddle \& Fenner, 2017). In other words, systemic problems of water security demand systems thinking-based solutions.

One of the systems thinking that emerged in the 1990s was Integrated Water Resources Management (IWRM) even though the concept can be traced back to the 1970s (Biswas, 2009; 2008). Since then it has evolved as a conceptual framework and underpinned the intricacies of water problems and decisions (Suhardiman, Clement and Bharati, 2015). In the developing countries, IWRM was hoped to 'increase water productivity and improve water quality' (Kurian, 2004), through overcoming the problem of institutions, coordination, and system failures. It is also believed to facilitate policy discussions, improve water resources management practices, and support education and capacity building (Grigg, 2014).

IWRM has been promoted as 'a silver bullet' to address structural and institutional crises of water resources management (International Network of Basin Organizations (INBOs) and Global Water Partnership (GWP), 2009). The mantra has attracted several developing countries to incorporate IWRM as a guiding principle for their national water policy and programs (Grigg, 2014; Adey, deFraiture and Mehari, 2016; Suhardiman et al., 2015), for two major reasons. First, in the early 1990s, IWRM was hijacked by the neoliberal resources democratization process and hence donors can only channel their funds and supports through 'integrated approach'- on the contingent of up-taking IWRM. Developing countries were forced to accept IWRM to secure funding and as a means to liberalize their water resources sector. Second, various donors, NGOs, and think tanks were strongly advocating and promoting the principles of IWRM as a panacea to curb water resources management crises in those countries. As a result, several countries have adopted IWRM in their policies and programs haphazardly without proper institutional setting. This affected water resources management in various developing countries by confusing its concepts. The concept of IWRM is so fuzzy that the issue of what to integrate, how, by whom, or where remain vague (Petit \& Baron, 2009).

The successes of implementing IWRM are mixed and hence contentious (Varis, Enckell and Keskinen, 2014). The practice of IWRM in developing 
countries to ensure water security had a major setback (Araral \& Yu, 2013; Koppen \& Schreiner, 2014; Suhardiman et al., 2015). Likewise, Smith \& JønchClausen (2012) reported that more than $80 \%$ of countries had tried to apply IWRM in their policies and strategies yet the success of the efforts are under scrutiny. To cite a few, IWRM has failed in Brazil where various barriers affected the integration of socio-economic aspects (Ioris, 2008). In the USA, IWRM has not penetrated deeply into the culture of water resources managers (Grigg, 2014). In Ghana, 'there is a conflict between the IWRM goal of integrating all water uses and sectors in the management of water resources and focusing on the prioritization of water delivery services' (Amma \& Gupta, 2012: 33). In Ethiopia, the failure of IWRM is attributed to the institutional failure and political commitment despite the fact that the policy alleged that the entire water resources process is based on IWRM (Adey, et al., 2016; Reta, Degefa and Getnet (2018). Consistent with these experiences, Biswas (2008: 21) curiously noted 'it is hard to find any water policy, program or project at any scale anywhere in the world that can be rated a score of 30 out of 100 on a scale of 1 to 100 (1 being no integrated water resources management and 100 being full integration)'.

In this paper, we argue that uniform institutional environments may not work in water resources development. The phenomenon of homogenizing institutions and recommending to fit all settings called 'institutional monocropping' (Ostrom, 2013) does not work. The IWRM in 'one size fits all' approach could disturb the basin system than creating integration. This is because a basin system is always dynamic as other systems or subsystems change within it. For example, under the circumstances of water insecurity, the way of thinking on water allocation and conflict resolution mechanisms could shift. The water users who often considered as beneficiaries under conventional perspective become 'customers' or 'clients' from system perspective as water availability moves from state of plenty to the state of insecurity (Saleth and Dinar, 2004). This also calls for concurrent system shift in water institutions.

Under such change in systems, the rules and regulations of water resources development, use, and distribution are often redefined which we call system dynamism. Under the system dynamism, the existing supply and demand changes so does the quality and quantity of water to reflect the reality on the ground. In contrast to the system perspective, in the Awash River Basin, the water and related institutions adhered to sectorial thinking. The governing rules and regulations are not in a position to balance demand and supply, as well as water quality and quantity. As the previous work of the researchers identified, financial and human capacity are the major constraints of Awash River Basin in addition to vertical and 
Reta Hailu, Degefa Tolossa \& Getnet Alemu

horizontal coordination failures (Reta et al., 2017). The problems have been triggered because of weak institutional capacity and poor enabling environments (Petersen-perlman, Veilleux, Zentner and Wolf, 2012) for adapting and implementing IWRM. Consequently, water is becoming scarce during the dry season and a surfeit during the rainy season.

Informed by an international sphere of influences, Ethiopia has formulated water resources management policy geared towards IWRM through River Basin Organizations (RBOs) as early as 1999 (Ministry of Water Resources (MoWR), 1999). The fundamental principles of IWRM in Ethiopia are aimed to guide equitable, sustainable, and efficient development, utilization, conservation, and protection of water resources in Ethiopia. The 1992 Dublin Principles and other international fora influenced the policy statement. The policy declared IWRM as a general framework and RBOs as a unit of IWRM. Water sector strategies, programs, and several laws and regulations followed the policy statements. The implementation of IWRM faced setback despite huge emphasis that IWRM is a remedy for water security in the basin context. As to our present knowledge, the efforts have neither instituted IWRM at the basin level nor provided any real guidance to the water professionals and practitioners as to how the concept can be operationalized. Particularly, IWRM has never been implemented in the Awash River Basin (Adey et al., 2016). The move towards IWRM must come up with an option.

Therefore, this paper seeks to answer the question how IWRM could be a roadmap to attain water security in the Awash River Basin. In order to answer this question, we need to ask two more questions. What to integrate? and how to integrate? While the first question tries to understand how the sectors and stakeholders work together, the second question addresses the mechanism to link and understand various sectors, actors, and water uses.

\section{Conceptual Framework}

In river basin context, IWRM is defined as 'a process that enables the coordinated management of water, land and related resources within the limits of a basin so as to optimize and equitably share the resulting socioeconomic well-being without compromising the long-term health of vital ecosystems' (INBO \& GWP, 2009:18). The definition left the concept for further interpretation remarking it as a 'process' like a 'big tent' (Grigg, 2014). It does not indicate how integration is possible - the question that matters practically! However, the process-oriented nature of IWRM provides an avenue for water sectors and stakeholders to interact and to create dialogues for joint action and collaboration. 


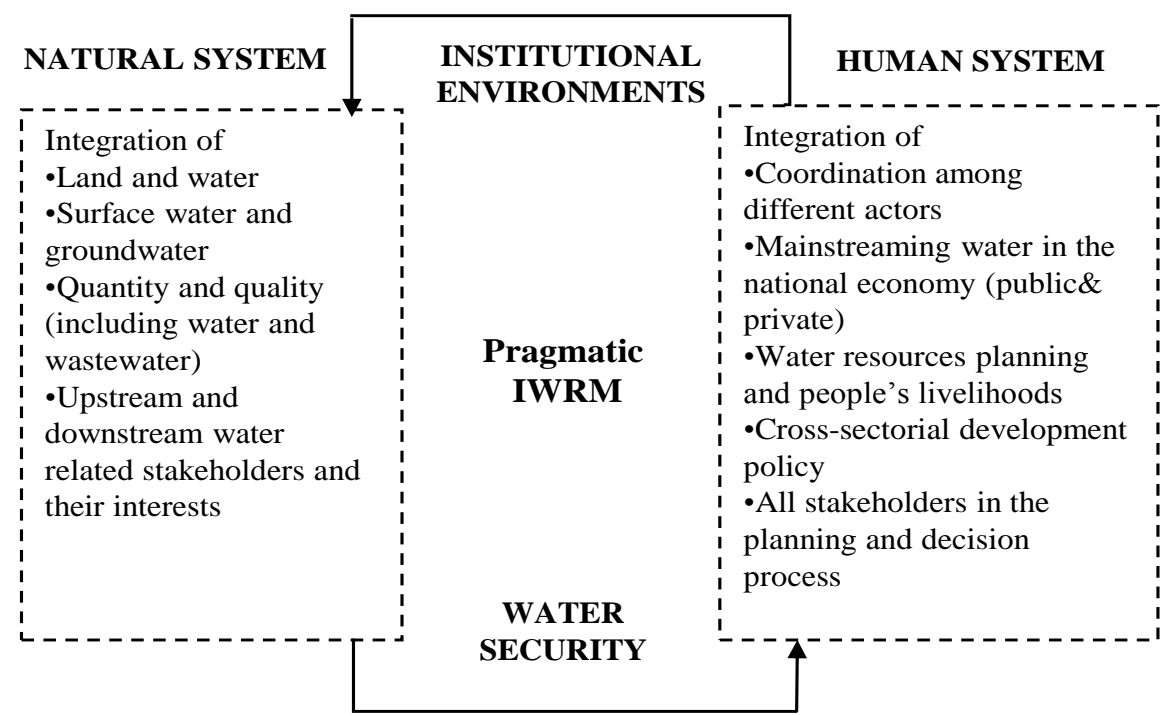

Figure 1: Conceptual framework to underpin IWRM pragmatically from systems perspective to attain water security (Source: Elaborated based on Jønch-clausen \& Fugl (2001))

To this end, the means to achieve water security must go beyond the conventional assumption of 'unfinished' concepts of IWRM. Amma \& Gupta (2012) underlined that the holistic and sectorial focused approaches in water service delivery seem to be irreconcilable. Thus, there is a need to shift from sectorial approach to systems thinking called pragmatic viewpoint of IWRM. Pragmatism according to this paper is an attempt to coordinate and integrate realistically the social system, human system, equity aspect, and political system (Simonovic, 2008). Pragmatism is a worldview of water resources management dealing with IWRM sensibly and realistically in a way that is based on practical rather than theoretical considerations. From operational point of view, pragmatism is also a means to reconcile various sub-systems within a system. In this basin, the basin is the larger system while the aquifers and surface water are subsystems within the context of the larger system. This concept departs from adaptive water resources management in the sense that adaptive capacity is ' $a$ link between vulnerability and resilience' to respond to socio-ecological system rather than integrated and holistic implications (Garfin, Scott, Wilder, Varady and Merideth, 
2017). This is the reason why this paper employed a holistic framework that can accommodate emerging issues of water resources security (Figure 1).

Essentially, one cannot avoid the generic principles of IWRM because they are demanding in context where the coordination is needed between resources (land and water), as well as among stakeholders on equitable resource access. Moreover, IWRM can induce dialogues among actors and maximize benefits from the basin system. The scientific community believes that the IWRM is emerged from system approaches that transposed integrated management into water resources (Petit and Baron, 2009). Thus, action-oriented arrangements to implement the principles and frameworks of IWRM that understand systems perspective are demanding.

Integration requires the inclusion and coordination of different systems at various levels (micro, meso, and macro). According to Jønch-Clausen \& Fugl (2001), the integration involves natural and human systems. The natural system encompasses availability and quality of water while the human system constitutes utilization of water resources, waste production, and pollution of the resources. IWRM concomitantly addresses the integration of natural and human systems, which in turn include the integration of various sub-systems as represented in Figure 1. In a pragmatic sense, IWRM negotiates among various actors, sectors, and their interests. It coordinates resources -land, and water, as well as among stakeholders who share these resources.

\section{Methodology}

\section{Study Area}

The Awash River Basin of Ethiopia rises from the highland plateau of West Shewa zone of Oromia Regional State. The main basin and major tributaries are located in Central Ethiopia. It flows through five Regional States (Oromia, Afar, Amhara, Somali, and SNNPR) and two administrative councils (Dire Dawa and Addis Ababa) (see Figure 2). The maximum and minimum temperature in the basin is 29 ${ }^{\circ} \mathrm{C}$ and $20.8{ }^{\circ} \mathrm{C}$, respectively, with an average rainfall of $557 \mathrm{~mm}$ (ranging from $160 \mathrm{~mm}$ in northern part of the basin to $1600 \mathrm{~mm}$ in the highlands of northeast of Addis Ababa) and evaporation of $1800 \mathrm{~mm}$ (World Water Assessment Program (WWAP) \& Ministry of Water Resources (WoWR), 2004). It is the highest evaporation area among the river basins of Ethiopia. The surface runoff is estimated to be about 4.9 Billion cubic meter $\left(\mathrm{Bm}^{3}\right)$, which is nearly $3.75 \%$ of the total annual renewable freshwater flow in Ethiopia (FAO, 2013; Hemel and Loijenga, 2013). The river faces both drought and flood phenomena due to extreme climatic conditions and water insecurity, which are challenging the livelihoods of 
people (FAO, 2013; Shimelis, 2012; Taddese, Sonder and Peden, 2005; Flintan \& Tamrat, 2002).

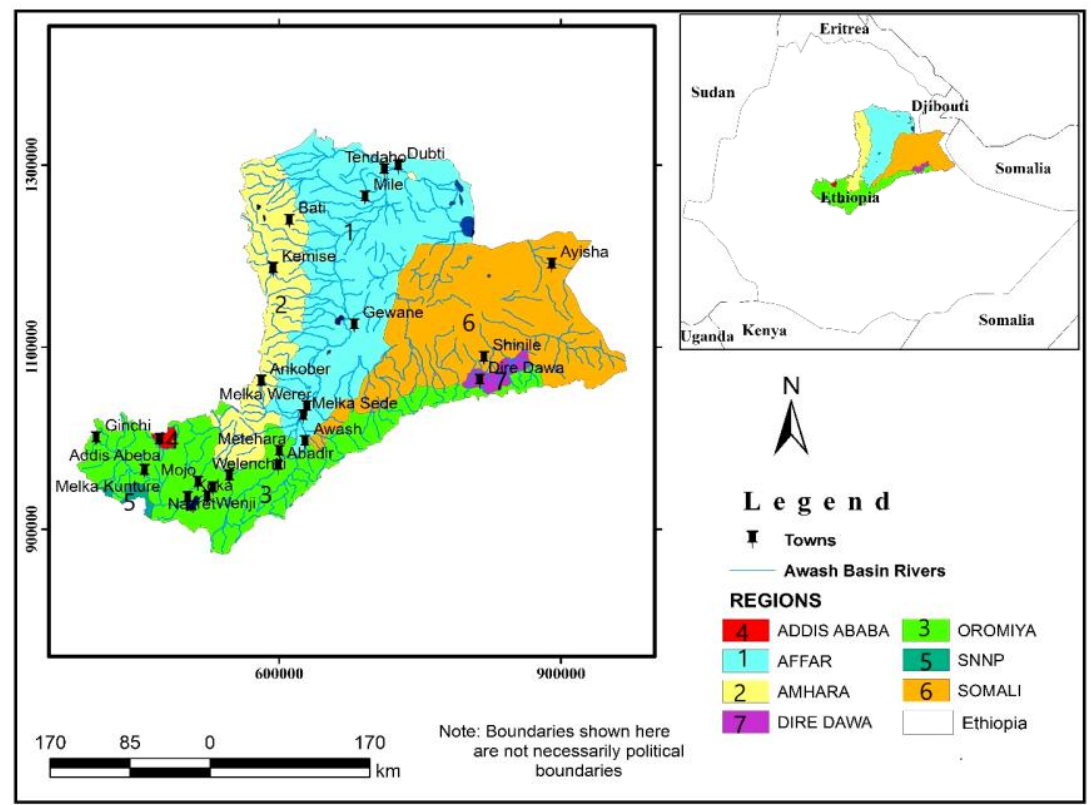

Figure 2: Administrative location and water bodies of Awash River Basin (Source: Reta, et al., 2017).

\section{Method of Data Collection}

The study generated data for this paper from household and institutional surveys, in-depth interviews with key informants, focused group discussions (FGDs), direct observations and workshop participants, and secondary sources.

\section{Expert survey}

First, the paper drew on the perspectives of water experts $(n=15)$ as a benchmark to understand and assess the existing situations. The experts have sent a structured questionnaire on the institutional performance in the Awash Basin. The questionnaire addresses water use categories, water quantity and quality, the linkage among actors, coordination, conflicts, and synergies among various uses and actors, accountability mechanism, responsiveness, actors' relations, information flows and challenges of water resources management, among others. The purpose was to obtain focused opinions and viewpoints from well-experienced 
Reta Hailu, Degefa Tolossa \& Getnet Alemu

experts (researchers, consultants, and practitioners). It helps to explore holistic and integrated resources management among various entities. This helps to comprehend and shed light on the enabling institutional environments in the basin.

\section{Household survey}

A case study of Fentale district from Awash River basin was employed to generate evidences on situations of various aspects of water resources management and its implications on household water security at micro level. We selected the district because of severe water crises that triggered frequent drought and environmental resources degradation.

The data was collected from 400 randomly selected households. The survey has collected socioeconomic and biophysical data. It addressed: (1) water resource availability, (2) access to available water, (3) purposes and means water used for, (4) capacity of household to manage water, (4) the ecological integrity of water, and (6) organizations and institutions mediating the process of water access and use. The design of the survey was primarily close-ended questions.

\section{In-depth Interviews and Focus Groups Discussions}

The interviews were conducted with 38 institutional representatives [academia, Donor, NGOs, CSOs, businesspersons, and local communities]. In addition, FGDs were held with various members of local community like Water Users' Association (WUAs), water committee members, elderly and women]. In order to manage both in-depth interviews and FDGs, checklists were developed with full protocol. The ethical standards were maintained; consents were obtained to record and transcribe the information using mobile phone and respondents name were kept anonymous.

\section{Direct Observations and Workshops}

Direct observations of industries, sugarcane estate and factories, plantations, irrigation infrastructures, water supply schemes, and dams were made. These have provided a first-hand understanding of the problems of water and its integration to other sectors. In addition, various workshops and stakeholders' meeting on water issues were supplemented to triangulate and validate some evidences.

Secondary sources and literature from various institutions' agendas, reports, memoranda, minutes, and other documents (project documents, workshop proceedings, journal articles, policy, planning, and strategy documents) and archives (water-related legislation and laws) were consulted, crosschecked, and 
triangulated with other sources. The data were collected between October 2015 and May 2017 at various levels, involving multi-scale analyses.

\section{Method of Data Analysis}

The data collected from households and actors was entered into SPSS Ver.22 and descriptively analyzed. The data from various informants and discussants, and other secondary sources were entered into Excel Spread sheet, thematically summarized, and content analyses were employed (Julien, 2008). Vensim Version 7.2 (Ventana Systems Inc., 2017) used to analyze linkages and relationships among the systems and subsystems. In addition, it was used to understand the dimension of the relationship among entities in the various systems and subsystems. Multiple sources of data were triangulated to verify, validate, and seek for convergence of some sensitive and contentious information that need cross-referencing and data triangulation (Creswell, 2014; Desai and Potter, 2006).

\section{Towards IWRM: Discrepancies and Prospects}

Ethiopia has set Ethiopian Water Resources Management Policy in 1999 and adopted IWRM as a general framework for water resources management. The fundamental principles are aimed to guide equitable, sustainable, and efficient development, utilization, conservation, and protection of water resources in Ethiopia (MoWR, 1999). Since its existence, the Policy did not achieve sufficient institutional performance against its core principles (Adey et al., 2016; Reta, et al., 2018). It only realized three River Basin Organizations; namely Awash Basin Authority in 2008, Abbay River Basin Authority in 2008, and Rift Valley Lakes Basin Authority in 2011. The latter two are not functioning. The Awash Basin Authority too could not put into practice the policy statements and principles of IWRM. In the policy document, the IWRM tenets have meritoriously ordered many of the recent trendy, fashionable, and politically correct but operationally fuzzy parlances.

Yet, the policy has gained tremendous applauses from donor agencies as it was fashioned with the parlances of IWRM. It was, thus, called 'comprehensive' and 'all inclusive' even without fashioning 'water security'. The policy was successful in assaulting the eye and thought of the donors and NGOs. Consequently, it secured incredible funding following philanthropic logic as Saravanan, et al. (2009) call it, including from the World Bank and UN agencies. It seems that the concept was included in the policy for the sake of attracting funds or to obtain greater national and international acceptance and visibility, and entice the 
eyes of the various donors. In reality, the statements in the policy are tremendously a rhetoric and the implementation has been so far weak.

The policy was turned into strategic and programmatic focuses. The strategy did not show the roadmap of IWRM: what, where, and how to integrate. The water sector development rather was taken by the wave of Millennium Development Goals (MDGs), with donors putting funds to it. MDG-7 aimed to ensure environmental sustainability that included a target to halve, by 2015, the proportion of people without sustainable access to safe drinking water and basic sanitation (WHO/UNICEF, 2014). It mainly focused on Water Supply and Sanitation (WaSH) without proper coordination among pertinent actors until 2013 when WaSH Implementation Framework (WIF) came into existence. WaSH was a vehicle routed across all aspects of water discourses in the country. As a result, Ethiopia has achieved MDGs target two years before actual plan set (Ibid). Even though MDGs has increased water supply coverage from merely 17\%, in 1990sthe lowest of Sub-Saharan African- to 65\% in 2015, the goal to reach water security is remaining slothful due to a temporal and spatial variability of rainfall and institutional barriers.

Improving $\mathrm{WaSH}$ access and coverage is not an end for water security because the state of water access, availability, and safety is so fragile that sustainability issues surfaced. For example, a case study of Fentale district showed that about $63.5 \%$ of the respondents perceived the available water has repulsive test; $54.5 \%$ felt unpleasant odour; and $51 \%$ reported that it is dirty and cloudy in colour. The finding further revealed that only $49.3 \%$ access to some sorts of sanitation (1.8\% use flush toilets, $4.5 \%$ access ventilated and improved pit latrine, and $43.3 \%$ use traditional pit toilet). Moreover, the practice of hand washing during critical time (after visiting toilet and before dinning) and disinfecting water for cooking and drinking were minimal, particularly during water scarcity. Thus, improving water quality and sanitation practices found to be essential aspect of ensuring the safety of available water, which needs further awareness raising in the community.

It was also observed that the seasonal variability ${ }^{1}$ is high. The annual rainfall of the district during normal year is $560-631 \mathrm{~mm} / \mathrm{year}$ and yet there was

\footnotetext{
${ }^{1}$ There are four seasons in the area: Ganna (June-August) the long rainy season, Bira (September to November) -short dry season, Bona (December to February)- long dry season, and Arfasa (March-May)- the short rainy season. However, in this study, we combined the four seasons and considered rainy season in the area between March and August whereas dry season between September and Novembers.
}

62 
insufficient rainfall in the last two years, for instance. Some pastoral kebeles are suffering from water resources scarcity throughout the year. It is worth nothing that the households in the pastoral kebeles do not practice crop production, as they could not access to irrigation schemes available in the district. In 2016, the failure of rainfall caused serious drought in the district, which affected water resources availability. Figure 3 exhibits proportion of water scarcity by months in 2016 .

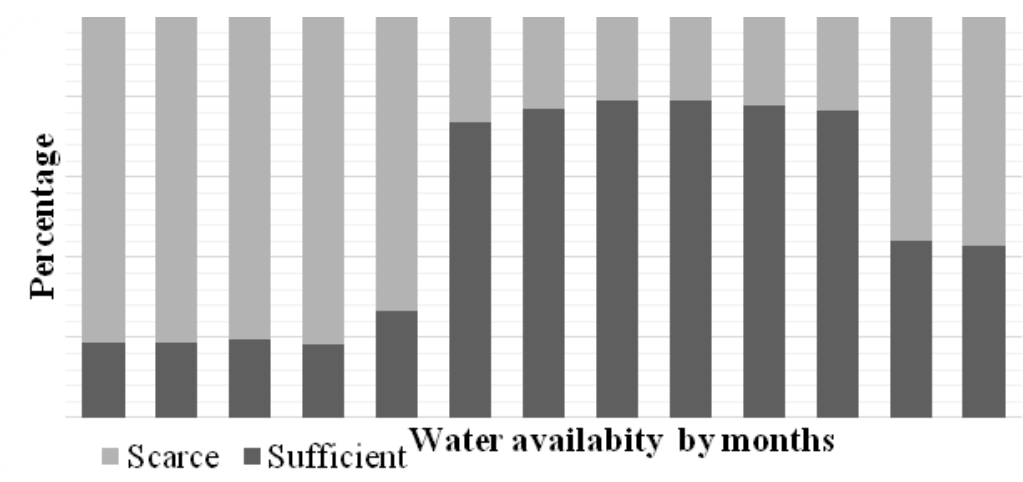

Figure 3: Seasonal variability of available water in the district (Fieldwork, 2016)

Moreover, the existing schemes were not designed for multipurpose uses, which deepen the water stress (Figure 4). Thus, water resources management problems need to be understood holistically from the lens of system approach. 

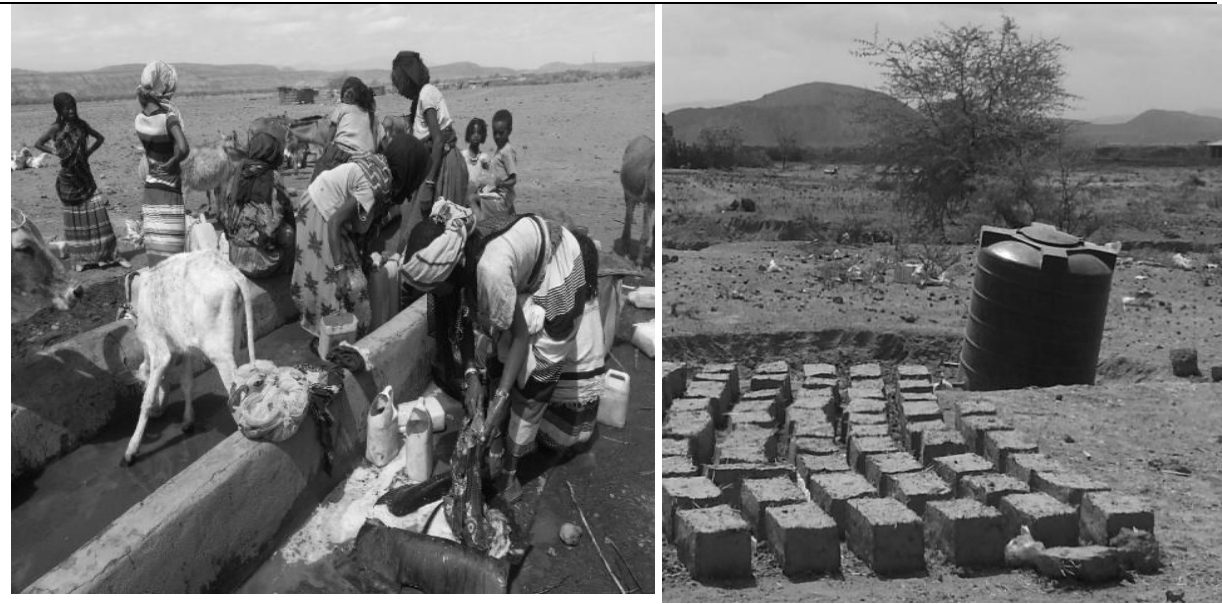

Figure 4: The figures show livestock and domestic use, and brick making) in Harokersa village of Fentale district in the Awash Basin (Fieldwork, 2016)

A case study of Fentale district from the Awash Basin depicted that water from taps, irrigation canals, wells, boreholes, rivers, streams, lake, and rainwater collection are the sources of water in the district. These sources are used for domestic, livestock, agricultural, and other purposes. Irrigation canals, rivers, streams, and lakes are the major sources of water for the above identified purposes. For example, about $40 \%$ of the households in Fentale district obtain water for domestic purpose from irrigation canals. Similarly, the major source of water for livestock and agricultural production is the Awash River. About $15.3 \%$ of households in Fentale obtain water from taps (private and public) while $16.8 \%$ rely on boreholes. The practice of rainwater harvesting is very low. It covers only 3\% of water sources (see Figure 4). The finding concurs with the paucity of IWRM to meet various needs and interests. The tradeoffs and synergies of various sources of water and multiple uses are unclear and intricate that can only be visualized from a system perspective. 


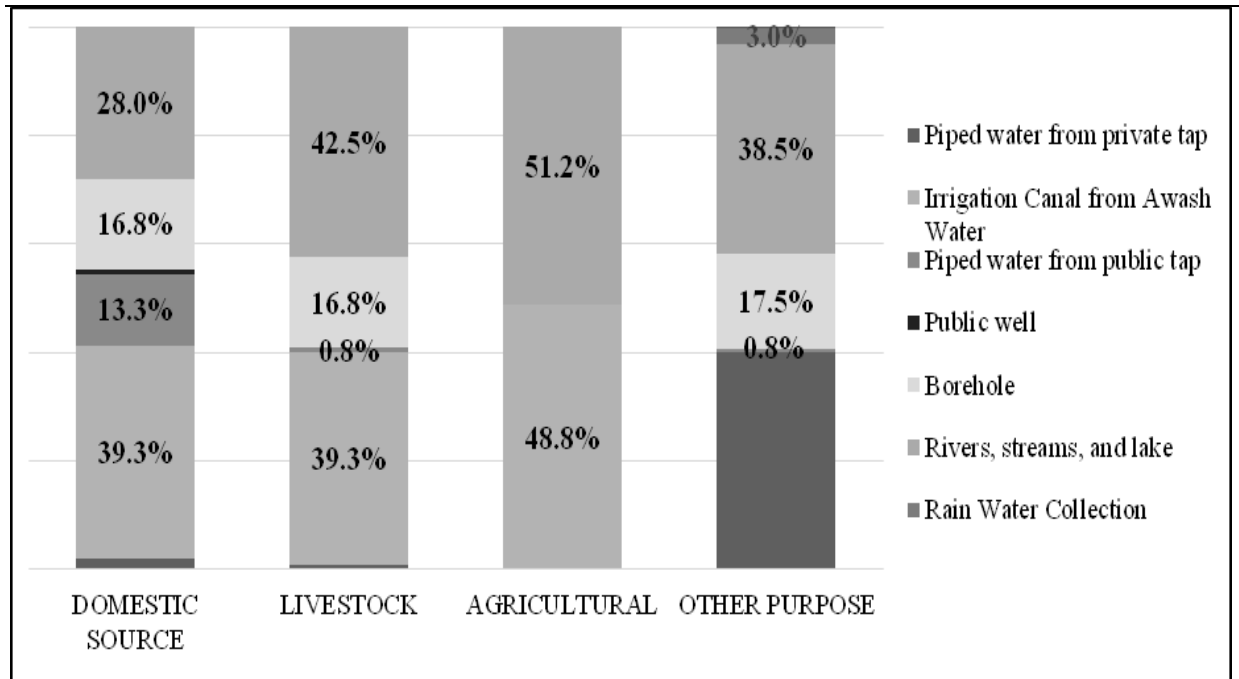

Figure 5: Source of water for different purposes in the Fentale district of Awash Basin (Fieldwork, 2016)

In the Awash River Basin, the majority (68.64\%) of the irrigation schemes in the basin is dominated by community irrigations. i.e community irrigations share 109,503 ha out of the total 159,533 ha irrigated. The commercial farmers share $17 \%$ of the total irrigated land in the basin (FAO, 2013). The community irrigations are controlled by Water User Associations (WUAs).The irrigation systems are governed by the WUAs. The WUAs do not pay for water construction, use, and management. However, the members contribute for Operation and Maintenance (O\&M) of the schemes. Governed by their own bylaws, sometimes, WUAs collect fines from water users. Yet, the fees collected from water users such as state farms, private, and small-scale farmers are inadequate to manage water resources on sustainable base. Moreover, the allocation of water resources requires the knowledge of crop water requirements to determine the demand for water. The farmers do not have such technical knowledge. They arbitrarily apply water on their fields. There is, therefore, a need for adequate technical support at the farm level from the agricultural extension agents to give technical support to farmers in determining water requirement for individual farm plots and to the whole irrigation scheme so that the water supplied from irrigation structures (canals, etc.) are efficiently used. However, there is a lack of adequately trained irrigation extension agents at the kebele level to carry out this work. As a result, some water users 
complain the scarcity of water in the basin not because of the dearth of resources but scarcity emerging from poor management and conservation.

Admittedly, the Awash River Basin Authority (AwRBA) is striving to coordinate various users because it is a key mission of the Authority. It has a broad vision to see the basin as a model river basin in Ethiopia, in which comprehensive and IWRM system are established. The Authority is swinging with values such as innovative and creative, participatory, equity and accountability, quality first, availability, environmental sustainability and development, continuous learning, teamwork, and detesting corruption in the River Basin Organizations (RBOs) context. The values seem to promote IWRM. Nonetheless, beyond notices on the office wall, these values are neither implemented nor internalized into day-to-day activities of the office. IWRM principles are not envisioned systemically and uniformly in various hierarchy and sectors. The stakeholders believe that the implementation of IWRM should be through a bottom-up and decentralized approaches. Until now, the push to IWRM is mainly top-down. It rarely consulted the regional, district, local, and other collaborative stakeholders. In addition, IWRM is affected by uncoordinated interventions as illustrated by an expert at District Water Office in Amibera. He reported that:

\begin{abstract}
Water sector is very delicate here because of water scarcity. Yet, water planning, management, and decision-making processes are increasingly messy. We received trainings on integrated principles. These trainings were rarely implemented as we already knew the principles as sermons of policy statements. Various stakeholders did not sustain their interventions in the area and end-up with false promises. Sometimes, we meet once a year; we talk about principles and depart to meet after a year. The interventions so far are not integrated and the principles are never practiced. Thus, everything is a rhetoric and thus we are far from rational and efficient water resources management despite the growing challenges.
\end{abstract}

Despite the fact that there was huge focus on water infrastructures (dams, irrigation facilities) and increased WaSH coverage in the last 18 years, little successes have been documented regarding IWRM at the basin scale as the policy is even biased towards domestic water supply under the guise of MDGs. The interests and priorities of these stakeholders could not be addressed visibly in the process since they are hesitant to the outcome of IWRM. For example, a group interview (4 men and 3 women) made in Dire reservoir area, one of the major 
water supplier of Addis Ababa City, agitatedly revealed a frustration and questioned how IWRM is promoted in the area as follows:

\begin{abstract}
People from NGOs, Federal governments, and Addis Ababa City Administration dictate us to manage watershed surrounding the reservoir. We make our livelihoods from farming, grazing, quarrying, etc. surrounding the reservoir. We cannot stop these because these are the sources of our livelihood. We need alternative sources of livelihoods to stop farming or quarrying and to protect the dam. As you can see we do not have water supply services although the dam is here and the pipes pass through our home yard to serve the City. We are not benefitting from the dam. Thus, it is difficult to talk about integration under such circumstances.
\end{abstract}

In the Awash River Basin, several Dutch organizations such as Water Board Authorities, Meta-Meta, International Water and Sanitation Centre (IRC), Vitens Evidas International, Dutch Wash Alliances, among others have been framing institutional arrangements that promote IWRM in the basin through customizing the Dutch model of water resources management. Paradoxically, the interventions to support IWRM were mainly project oriented. When the projects have finalized and the external funds ceased, often before internal capacity developed, IWRM halted. Moreover, the interventions did not address the underlying systemic reasons for poor implementation of IWRM. The policy as well as the subsequent proclamations and regulations did not explicitly address the socio-political system complexity of water resources management in the Basin. The policy faced the difficulty of harmonizing both- political and hydrological boundaries where both Federalism and River Basin Organizations co-exist.

The proclamation and regulation are based on the federal system, as the basin constitutes five Regional States (Oromia, Amhara, Afar, Somali, and SNNPR) and two City Administrations (Addis Ababa and Dire Dawa). However, when it comes to water resources management every region plans water resources development and management separately in the same basin. In other words, the Federal Government follows river basin planning approach whereas Regions and Cities have their own specific plan regardless of RBOs. It seems to us that both systems exist but misread each other and that made IWRM a daunting task for stakeholders. The basin also comprises pastoral, agro-pastoral, rural, urban, highland, arid lands, smallholder farmers, large-scale farms, and estates. These have caused sociopolitical system complexity due to heterogeneity of the context, which further triggered several subsystems within the larger basin system. The existing policy, 
proclamation, and regulations either did not recognized the complexity or overlooked the reality on the ground. Given this complexity, interviews with some higher officials revealed that IWRM would be difficult under the present institutional structure. Hitherto, fragmentation of efforts exacerbated water insecurity in the basin. This calls for holistic approach to manage land, water, various uses, and users.

Generally, the study observed that setting policy statement alone could not guarantee the implementation of IWRM. It can be argued that one of the mechanisms to overcome such discrepancies is to approach water resources management as a system that brings wider stakeholders on board at multiple scales. In other words, implementation of IWRM relies on discussions and consultations of different actors, and consideration of multiple uses and sectors. The approaches so far followed have overlooked these aspects. The undeniable fact is that there are various efforts to instigate IWRM. However, they have neither been instituted at the basin level nor provided any real guidance to the water professionals and practitioners as to how the concept can be operationalized.

Since the late 1990s, two trends were observed. Donors and NGOs as a part of international commitments such as achieving MDGs dominated the first scenery. The second was ambitious state projects, which targeted the big dams for hydropower and large-scale commercial farms. These big dams require huge money. Ironically, it is 'putting all eggs you have in a basket'. These projects have also been criticized for social and environmental externalities (Carr, 2017). The impact is particularly execrably high when compensation for the displaced people from their livelihoods and land resources are barely paid. In doing so, the approach so far followed overlooked the balance among multi-purpose uses, sectors, and actors that water scarcity and stress have growing in the basin. At the national level, therefore, there is a need to reconcile the federal institutions, Awash Basin Authority, and regional bureaus to promote pragmatic IWRM.

\section{Systems Approach to Water Resources in the Basin}

The basin system can be categorized as natural and human systems (Jønch-clausen \& Fugl, 2001). Each is a part of larger basin system functioning as independent system but interacting with one another. The natural system involves various biophysical elements (the groundwater, the land and water resources, upstream and downstream, and water quality and quantity sub-systems) that affect water security. The human system constitutes various socioeconomic realms such as various stakeholders, water use purposes, sectors, and interests, which have their own subsystems within the human system. It is fundamentally necessary that the 
two systems operate holistically and synergistically for functioning of the whole basin system. The proper functioning of the systems, of course pragmatically, enhance IWRM and hence water security as discussed below at some lengths.

\section{The Natural System}

Within the groundwater subsystem-aquifers, there is lacuna of rules or laws regulating and governing the subsystem. Standards and governing laws for extraction, drilling, and use of groundwater in the basin are not clearly defined the the subsystem is dominated by a temptation of free-riders $^{2}$. Any user can drill water either using rig machine or hand-dug for any purpose if they can afford the cost of extraction. The groundwater engaged a range of water users from deep drilling for irrigated agriculture to shallow well for domestic purposes. Interviews with experts attested that there are no collective actions on the groundwater management (allocations, utilization). The action of one actor is unknown for the other actors. Neither fees nor tariffs are set for and collected from users. Some are licensed others are not. For example, several medium and small-scale agricultural land operators, as well as industries-the massive water users-are not licensed and provided with water use permit. This implies the extent to which the key stakeholders completely overlooked groundwater governance in the basin. It is a conspicuous manifestation of institutional failure in the Awash Basin (Reta, et al., 2018). Thus, the exploitation of groundwater subsystems are uncoordinated and become a 'tragedy of the common', which needs groundwater governance and proper institutional framework.

The study also revealed that surface water resources subsystem is poorly managed and allocated, in which collective actions are not operational. Surface water subsystem in the basin comprises all rivers, lakes, ponds, dams, and other storage due to runoffs and/or groundwater recharges. First, it is the major source of commercial farmers to irrigate farms through pumping out the running river. About 97.3\% of irrigated areas are furrow/surface irrigation systems. This irrigation system is inherently inefficient in terms of water use. FAO (2013) estimated that the efficiency of furrow irrigation in the basin is about 30-40 \% compared to 80$90 \%$ of sprinkler and $90-95 \%$ of drip systems. Yet, a few commercial farms have

\footnotetext{
${ }^{2}$ A free-rider is somebody who exploits the common pool resources such as water without taking into account its sustainability. The free-rider uses resources at the cost of the others. When the free-riders prevail, the other users are also triggered to increase the exploitations of the resources because it seems better to take the last bit of a resources before it is finished, rather than to have nothing at all (Savenije \& Hoekstra, 2009:39).
} 
Reta Hailu, Degefa Tolossa \& Getnet Alemu

introduced drip (1.9\%) and sprinkler (0.8\%) irrigations. These farms engaged in high-value crops including floriculture, sugarcane plantations, fruits, and vegetable production. Drip and sprinkler irrigation types can substantially save water but water governance system is not driving towards technology introduction and promotion due to lack of incentive mechanisms. Second, appropriate water pricing is not only essential but also a prerequisite for efficient water use through triggering market mechanism (Jiang, 2017). Ingram, Weatherford and Cortner (1984: 332) also noted that 'water pricing can be expected to facilitate entry into the market by new users, at least in the short term, and to lead to greater efficiency in use'.

The water pricing mechanism can integrate water as a natural resource with a significant economic value that ensures social equity. It promotes efficient water use to avoid scarcity and pollution that centered on the affordability of the fee to overcome inaccessibility. Furthermore, proper water pricing mitigates abuses through taking into account contextual tariff setting. Although the Ethiopian Water Management Policy has put the economics of water cost and pricing, which valued water as economic resources as much as it emphasized as social values, the pricing system in the basin is working against the principle of IWRM. It is not treating water as an economic good.

Still, there is limited water saving methods and practices in the Basin due to poor pricing mechanisms. Some irrigated farms are not paying water charges at all and a few are paying a nominal price of $0.13 \mathrm{US} \$ / \mathrm{M}^{3}$. Large-scale farms can easily access water at a cheaper cost that there is no adequate incentive to push them to invest on water-saving irrigation technologies such as sprinkler or drip irrigation. While the cost recovery fees have been well established for urban water supply since 1999 with respect to drinking water, little progress has been made for rural water supply (drinking and livestock uses) and irrigation water. Rural drinking water is based on the principle of covering operation and maintenance (O\&M). Until now, there is no clear pricing policy for large-scale irrigation schemes, industries, fishery, water bottling, pollution control, hydropower, and recreational uses of water in the basin. The Awash Basin Authority attempted to collect some tariffs for flood protection though it is insignificant with the increasing flood frequency and coverage. Moreover, there is an intention that the active involvement of government is to support those who could not pay for water resources development. Because the poor community could not pay for O\&M, the policy encourages full cost recovery and promotes cross-subsidization in the urban area. The policy speculated that all pricing schemes should take into account the willingness-to-pay by users as a tool to encourage water resources sustainability. 
Table 1: Water pricing system in the Awash River Basin ( $X=$ Not accounted, $\checkmark=$ Accounted)

\begin{tabular}{|c|c|c|c|c|c|}
\hline $\begin{array}{l}\text { Pricing } \\
\text { system }\end{array}$ & Irrigation & $\begin{array}{c}\text { Domestic use } \\
\text { Urban }\end{array}$ & $\begin{array}{c}\text { Domestic use } \\
\text { Rural }\end{array}$ & $\begin{array}{c}\text { Industrial } \\
\text { Use }\end{array}$ & $\begin{array}{c}\begin{array}{c}\text { Other } \\
\text { uses }\end{array} \\
\text { us }\end{array}$ \\
\hline $\begin{array}{l}\text { Full cost } \\
\text { recovery }\end{array}$ & $\mathrm{X}$ & $\checkmark$ & $\mathrm{X}$ & $\checkmark$ & $\mathrm{X}$ \\
\hline $\begin{array}{l}\text { Partial } \\
\text { recovery }\end{array}$ & $\checkmark$ & $\mathrm{X}$ & $\checkmark$ & $\mathrm{X}$ & $\mathrm{X}$ \\
\hline Full subsidy & $X$ & $\mathrm{X}$ & $\mathrm{x}$ & $\mathrm{X}$ & $X$ \\
\hline $\begin{array}{l}\text { Operation \& } \\
\text { Maintenance }\end{array}$ & $\mathrm{X}$ & $\checkmark$ & $\checkmark$ & $\mathrm{X}$ & $\mathrm{X}$ \\
\hline $\begin{array}{l}\text { No clear } \\
\text { pricing policy }\end{array}$ & $\checkmark$ & $\mathrm{X}$ & $\checkmark$ & $\mathrm{X}$ & $\checkmark$ \\
\hline
\end{tabular}

Source: Survey of Actors $(n=15)$

However, we found out that most users are not paying in accordance with the value of water. While the smallholder farmers (both for modern and traditional irrigation), artifacts, mining, brickmaking, and other productive purposes can use water free of charge, the pricing mechanisms for commercial and industrial purposes are vague and inconsistent. Some large-scale private farms and state sugarcane plantations freely divert or pump out water directly from the river. Industries that can also dig their own medium and deep well still do not pay water extraction fees and of course are not licensed. The permitting and licensing of the surface water for the various purposes were also not uniform. In the urban water supply system, the surface water is so poorly managed that some waters are stolen, illegally connected, or wasted. One such indication is the high Non-Revenue Water $(\mathrm{NRW})^{3}$ in major cities. For example, in Addis Ababa City where there is a growing water scarcity, NRW is estimated at $36.5 \%$ (Addis Ababa Water Sewerage Authority (AAWSA), 2011). This affects domestic water security of other residents of the city and a community where the water is originally extracted.

As the value of water is undervalued, the existing water resources could be mismanaged and abused. This gradually induces pollutions and scarcity. Water price for irrigation, domestic for urban, domestic for rural, and industrial uses are rarely revised to reflect the changing cost of water management and scarcity value of water. The water pricing policy in the basin needs to be reconsidered so that the

${ }^{3}$ Non-Revenue Water (NRW) is water that has been produced and is "lost" before it reaches the customer. Losses can be physical losses (leaks) or apparent losses (theft or metering inaccuracies). 
value of water would be released at policymaking level. Besides, the pricing system must emphasize irrigation and industrial water uses as large-scale users.

In addition, the effectiveness of water policy in promoting technologies, extension, and waste water recycling are non-existing. The installations of water measuring devices are insufficient. Some installed devices are not functional during data collection. At the time, there is no technology to estimate water use of the major users in the basin. Interviews with stakeholders in the basin confirmed that most water users such as industries/farms, households, and urban wastes are directly releasing solid and liquid wastes, as well as effluents to the water bodies in the basin without treatment or any attempt for recycling. The irrigated farms are expanding in leaps and bounds but not hand-in-hand with the advancement of technology to save water, to monitor water uses, and to minimize pollution of surface and groundwater systems. The rush to expand irrigated farming practices at Metahara, Abadir, Tendaho, Amibera, and central highlands would lead to perils without proper collective actions. The expansion of the hypersaline lake Beseka that intrudes into the river (diverted to the main Awash River below Methehara Sugar Estate) from the previously closed lake has also been a major concern and compromising the water quality in the lower basin. The extreme hydrological phenomenon such as floods and droughts has evicted several people as they are not properly managed. The major reason is that pertinent institutions and actors are not collaboratively working together towards an IWRM.

The general picture in the basin showed that water pricing policy is haphazard and not systemic (Reta, et al. 2018). The uncoordinated water pricing system has discouraged technical innovation for water resources management in addition to aggravating 'tragedy of the common'. This gradually induces pollution and scarcity of both the surface water and groundwater subsystems as the relationship and integration of the two subsystems received little attention. Informants agreed that low irrigation technology coupled with inconsistent regulatory mechanisms for water abstractions, pollutions have affected the integration and management of surface and groundwater. Furthermore, it affected the quality of water available to people for various purposes. Based on fieldwork, we have established the challenges of groundwater and surface water integrations as shown in Figure 6. 


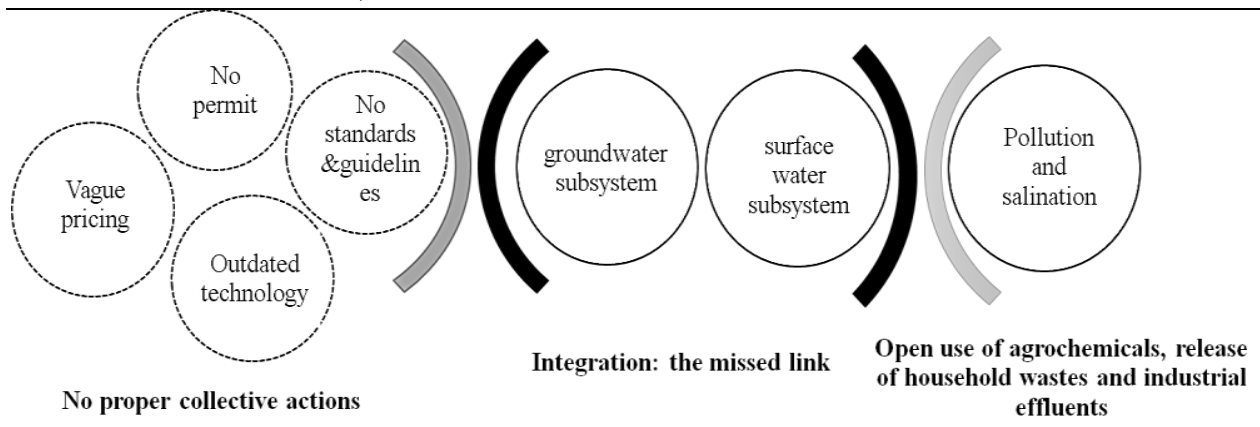

Figure 6: Relationship between groundwater and surface water subsystem and factors affecting them

The natural system also depends on how the land and water resources managements are properly and coherently integrated. Land degradation is the major problem in the Awash Basin (Hassen, 2004) due to deforestation, urbanization, and intensive cultivation. As such flooding during excessive rain and drought during water scarcity often hit the entire basin system. Such phenomena are key causes for water quality deterioration and diminishing water quantity. In addition, the upstream-downstream dilemma has hardly been noticed in the Awash basin system though it is critical as it cripples down the state of water security. The downstream users believe that the actions of upstream water users have affected negatively the quantity and quality of water available to them. Industries are releasing effluents; agriculturalists use agro-chemicals recklessly; cities dispose all sorts of wastes directly to water bodies; and land and water resources management and conservations are inadequate that the downstream actors are suffering from pollutions, water scarcity, and floods.

\section{The Human System}

Within the human system, complex realities are prevailing and emerging. This is because diverse behaviors of the actors, various interests, and uses are central to the basin management (Reta, et al., 2017). This system is also so dynamic that it poses complexity and non-linearity in interaction (Burns, 2007). For example, the interest of pastoralists in the basin system conflicts with irrigators who are engaged in agriculture and delineate their space. This is mainly not only due to fierce competition over water access but also as a result of land resources within the enclave of the key grazing areas, which the pastoralists utilize rotationally between dry and wet seasons. Likewise, the agriculturalists see pastoralists as 'antidevelopment' on erroneous perception. They believe that pastoralism is not 
feasible nor contribute to agricultural development so that agriculturalists priority must come first. The other interaction in the basin is a grave competition between the large-scale and small-scale irrigators over access to both land and water. Most small-scale irrigators are early settlers while large-scale famers are late comers in the form of 'investors'. Some of these large-scale farms are owned by the state. Recently, some of them are privatized. The Kereyyu and Afar pastoralists have already started irrigation agriculture. As a result, during the dry season- December and May, there is always water scarcity. Water scarcity during this time often escalates conflicts to the extent of water looting and violence. Sometimes, the competition for water leads to the damage of irrigation canals. It affects the livestock and drinking water access. The private sectors including the industrialists and service providers are complaining of water scarcity. They stressed that public sectors responsible for water resources management are weakly organized, slow response and unable to ensure accountable to rampant water crises.

Research, extension, and education are essential entities to generate knowledge, disseminate, and raise awareness about IWRM. They are also expected to carry out researches and document practices and challenges. The finding came across that research and training institutions in water sectors are often relying on donors and state funding to carryout research and trainings including the AwRBA. The AwRBA is a principal body assigned to undertake research and development regarding the basin. Given the staff and financial capacity, the Authority did not implement any groundbreaking research, development, or technology generation. Interviews with experts and stakeholders demand water use related awareness creation, training, and extension advisory services. However, there are sporadic studies by academician and Regional States for specific purposes. Thus, the AwRBA did not link itself with the regional and local governments, communities, and stakeholders including academic institutions.

Despite the fact that the public sectors have recognized the problem of water resources crises in the basin, there are limited investments on technological solutions to manage and conserve the resources in an integrated manner. For example, the management of solid and liquid waste is insignificant. The government mobilized community for mass campaign to carry out watershed management. This campaign based watershed management is unorganized and does not engage relevant stakeholders. It was merely perceived as the onus of smallholder farmers on a plot basis. Post watershed development was rarely monitored. Perhaps, the efforts so far made by donors, NGOs, and CSOs to support water access for domestic, livestock, and small-scale irrigation, and other 
productive uses should be the central part of the human system, which need to be seen pragmatically.

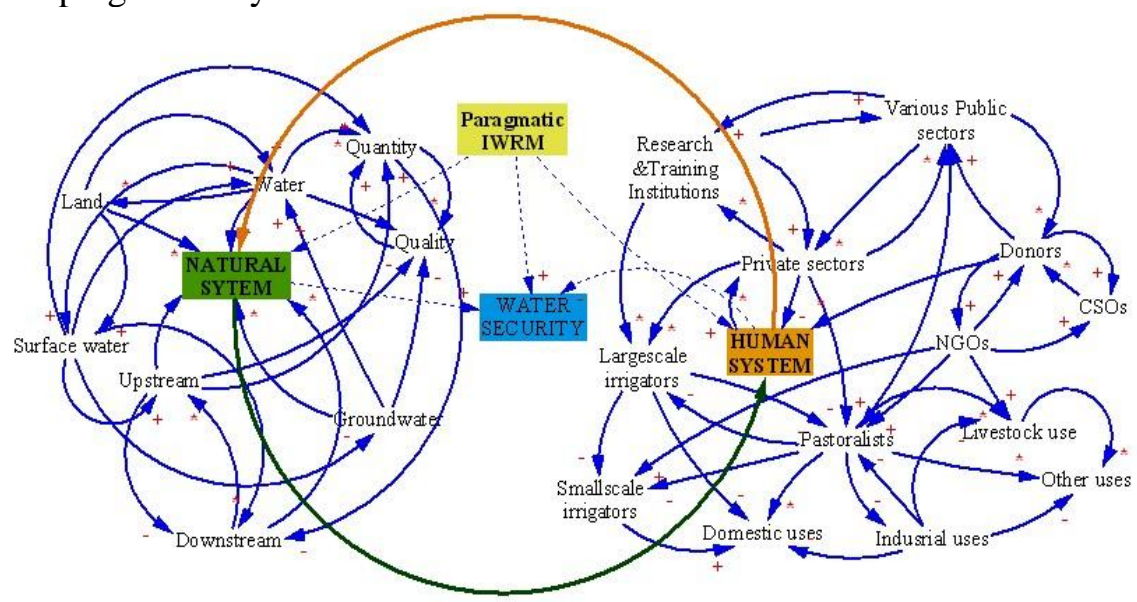

Figure 7. System approach to water resources management in the Awash River Basin. The (+) sign donates positive relationship among elements in the particular system. The (-) sign represents negative relationship. The $(*)$ shows possibility of both relationships. The broken line indicates the interaction of various systems to water security while the bigger loop connecting natural system to human system (green and orange) show the loop that back and fore system linkages that can occur holistically, respectively)

(Source: based on field data (2016).

As shown in Figure 7, the interactions of various subsystems among each other and within the particular human and natural systems have complex causal relationships. While some elements in the particular system affect the others negatively, some have positive relationships. Some have no relationships. Still, neural links prevail due to poor collective actions, and poor system integration and management. These suggest the weak integration between various systems. Therefore, integration requires a systemic means to bring the links among the entities as pragmatic as possible so that the entities contribute to the natural and human systems and thereby the whole basin system.

\section{Search for Enabling Institutional Environment for IWRM}

The institutional environments in the basin are always in motion with the changing political, economic, and social circumstances. The setting up of enabling environments should not be sudden, both physically and institutionally because it further upset the existing institutions. This paper is not proposing institutional 
change as it is not always demanding. Moreover, institutional changes may not necessarily yield positive outcomes. There are associated risks such as dismantling existing institutions exacerbate inequalities in water access, trigger environmental problems, and may create conflict of interests, among others. We rather argue that institutional change is desirable when it maximizes the goal of water security.

The two broad institutional change environments were analyzed using five criteria developed by Saleth \& Dinar (2004; 2008). Accordingly, the percepts on the enabling institutional environments for IWRM were weighed at Likert scale of five drawing on the indicators. The scores of the scale were converted to percentage. The first criteria is physical institutional environment in terms of ability to bridge overall demand-supply gap, physical health of water development projects; conflict-resolution efficiency (low cost and less time), smoothness of water transfers across sectors and regions, and smoothness of water transfers between users. The aggregate result gave $46 \%$ of possible capacity. The second is financial enabler that encompasses actual investment vs. investment requirements and cost recovery vs. expenditure, which scored $42 \%$. The third is economic aspect that rates the extent to which water prices cover supply cost and extent to which water prices cover scarcity value. In terms of meeting economic efficiency, it is perceived to be just $40 \%$ of what it ought to be. The forth is equity issues among regions, sectors, and different stakeholder groups which remains lower than the average and maximum expected values. The final is progressiveness of water institution that takes into account factors such as effectiveness, flexibility, adaptability, technological applications, innovation, and openness to change, which scored the lowest of all criteria and $40 \%$ of maximum value. 


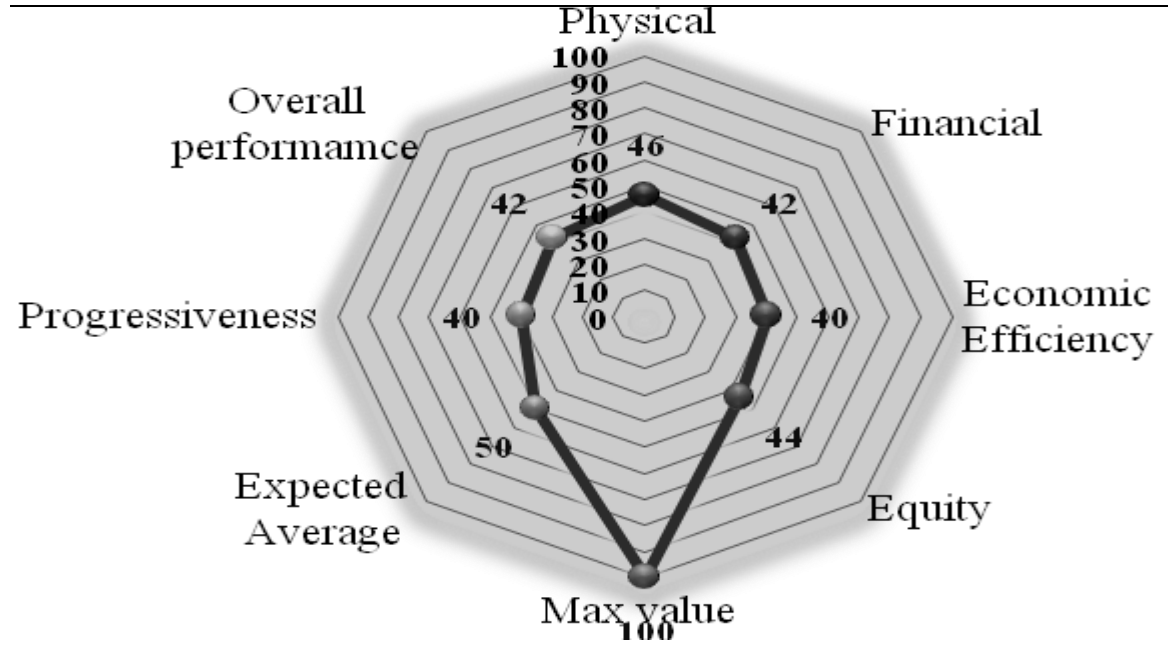

Figure 8: Performance of institutions in the Awash Basin (Fieldwork, 2016)

The result showed that the performance indicators of all institutional enabling environments have rated below the expected average value (50\%) with the overall performance is still low (42\%), according to the perception of the respondents. Figure 8 is suggesting that the water institutions in the Awash River basin, as evaluated by the experts, are not to the expectation to ensure IWRM through safeguarding water availability, accessibility, and proper utilization on sustainable basis. There is need for further works to improve the enabling institutional environments to suit to IWRM.

To subsume, the survey of literatures and institutional reports, as well as interview with experts revealed that in the last 19 years, little successes have been documented regarding IWRM in the Awash River Basin of Ethiopia. This suggests that the rhetoric was not translated to practice and reality. It entails that establishing River Basin Authority is not a guarantee for water security though the River Basin Organization is a prerequisite for management, coordination, and administration of water resources.

\section{Conclusions and Further Implications}

This paper draws on IWRM as systems thinking that recognizes the issue of water resources management holistically as it engages multi-actors and multiple sectors with diverse interests and priorities. Most previous approaches and existing formal institutions in the basin have been cascading IWRM followed reductionism perspective and often rhetoric than action. The prevailing institutional 
Reta Hailu, Degefa Tolossa \& Getnet Alemu

arrangements did not favor the implementation of IWRM. It is necessary to invigorate and revitalize the 'old concept' of IWRM pragmatically to enhance water security at the basin level. Pragmatically working with various stakeholders could help IWRM to move beyond a fashionable, buzzword, and trendy concept to make institutions work for water security. Thus, this study observed the following:

- IWRM in Ethiopia has failed to be realized not due to lack of policy and advocacy issues per se but the shortfall of the contextual practices. The failure to balance the natural and human systems and subsystems along with reengineering the enabling environments are key reasons for the setback of IWRM.

- System complexity must be understood from system approach as the basin has diverse socio-political interests. The existing policy, proclamations, and regulations need to be revised or customized in this lens. Water insecurity is closely attributed to poor water resources management, which arises from the lack of capacity and technical gaps of WUAs, farmers, pastoralists, and agropastoralists. Therefore, there is a premier need to boost their capacity through awareness raising, trainings, and technical supports on water use and allocation.

Moreover, IWRM requires devising competent organizational framework through an institutional capacity building, enhancing management instruments to plan for IWRM, social change instruments to resolve conflicts, regulatory instruments to enforce water laws, and communication instruments to share and exchange information. Accordingly, pragmatic IWRM needs to be revitalized through:

- Establishing strong information based and evidence-based water use, allocation, distribution, and water-related risks to reverse negative linkages, strengthen poor interaction, and maintaining positive interfaces;

- Ensuring that budget and finance mobilized from donors, the public, and water users through considering water as economic goods as much as public goods;

- Creating awareness among stakeholders; encouraging the engagement of private sectors in water resources development and management; inculcating the culture of corporate social responsibility; establishing functional platform to cheer interactions and intricacies among the stakeholders; and

- Advocating IWRM pragmatically via enabling institutional environments in the basin context, and mainstream it to water and related sectors, actors, and users. 


\section{References}

Addis Ababa Water Sewerage Authority (AAWSA). (2011). Business Plan 2011 2020. City Government of Addis Ababa, Ethiopia.

Adey M., de Fraiture C. and Mehari. A. (2016). Integrated water resources management: contrasting principles, policy, and practice, Awash River basin, Ethiopia. Water Policy, (18): 335-354. DOI: 10.2166/wp.2015.049

Amma, N. and Gupta, J. (2012). Reconciling IWRM and water delivery in Ghana The potential and the challenges. Physics and Chemistry of the Earth 47-48: 33-45. DOI: 10.1016/j.pce.2011.06.010.

Araral, E. and Xun, W. (2016). Comparing water resource management in China and India: policy design, institutional structure and governance. Water Policy, 18: $1-13$.

Araral, E., Yu, D.J. (2013). Comparative water law, policies, and administration in Asia : Evidence from 17 countries. Water Resource Research 49: 5307-5316. doi: $10.1002 /$ wrcr.20414.

Biswas, A.K. (2008). Integrated Water Resources Management: Is It Working? Water Resources Development, 24: 5-22. doi: 10.1080/07900620701871718.

Biswas, A.K. (2009). Integrated Water Resources Management: A Reassessment. Water International (29): 248-256. doi: 10.1080/02508060408691775

Burns, D. (2007). Systemic Action Research: A strategy for whole system change. Bristol: The Policy Press.

Carr, C.J. (2017). River Basin Development and Human Rights in Eastern Africa-A Policy Crossroads. Geneva: Springer International Publishing.

Creswell, J. W. (2014). Research design: Qualitative, Quantitative, and Mixed Method Approaches $\left(4^{\text {th }}\right.$ ed.). USA: SAGE Publications, Inc.

Desai, V. and Potter, R.B (Eds.). (2006). Doing Development Research., UK: London: SAGE Publications Ltd.

Flintan, F. and Tamrat, I. (2002). "Spilling Blood over Water? The Case of Ethiopia". In K. Sturman \& J. Lind, editors. Scarcity and surfeit : the ecology of Africa's conflict (pp. 243-320). South Africa: African Centre for Technology Studies and Institute for Security Studies.

Food and Agriculture Organization (FAO). (2013). Coping with Water Scarcity, the Role of Agriculture: Developing a Water Audit for Awash River Basin $[A$ Synthesis report GCP/INT/072/ITA] FAO Ethiopia: Addis Ababa.

Garfin, G.M., Scott, C.A., Wilder, M., Varady, R.G., Merideth, R. (2016). Metrics for assessing adaptive capacity and water security: common challenges, diverging contexts, emerging consensus. Current Opinion in Environmental Sustainability, 21:86-89. 
Reta Hailu, Degefa Tolossa \& Getnet Alemu

Grigg, N.S. (2014). Integrated Water Resources Management : Unified Process or Debate Forum? International Journal of Water Resource Development, 30: 409-22. Doi: 10.1080/07900627.2013.877338.

Hassen, Y.K. (2004). Assessment of small-scale irrigation using comparative performance indicators on two selected schemes in upper Awash River Valley. [M.Sc Theses]. Alemaya University, Ethiopia.

Hemel, R. and Loijenga, H. (2013). Set up of a Water Governance Program in the Awash River Basin, Central Ethiopia [Assessment of Water Governance Capacity in the Awash River basin Report], Water Governance Centre (WGC): Den Haag.

http://www.iwmi.cgiar.org/assessment/files/pdf/publications/

Ingram, H.M., Mann. D.E., Weatherford, G.D. and Cortner, H.J. (1984). Guidelines for Improved Institutional Analysis in Water Resources Planning. Water Resource Research, 20: 323-34.

International Network of Basin Organizations (INBO) and the Global Water Partnership (GWP). (2009). A Handbook of Integrated Water Resources Management in Basins. Paris, France.

Ioris, A. (2008). The limits of integrated water resources management: a case study of Brazil's Paraíba do Sul River Basin. Sustainability: Science, Practice, \& Policy, 4: 4-11.

Jiang, M. (2017). "Towards Tradable Water Rights: Water Law and Policy Reform in China". Global Issues in Water Policy, 18: 13-42.

Jønch-clausen, T. and Fugl, J. (2001). Firming up the Conceptual Basis of Integrated Water Resources Management. Water Resource Development, 17: 501-10. doi: 10.1080/07900620120094055.

Julien, H. (2008). "Content Analysis" in Given, L.M. (Ed.) Encyclopedia of Qualitative Research Methods. Los Angeles: SAGE Publications.

Liddle, E.S. and Fenner, R. (2017). "Water point failure in sub-Saharan Africa: the value of a systems thinking approach." Waterlines, 36: 140-166. doi:10.3362/17563488.16-00022

Long, N. (2001). Development Sociology: Actor perspective, ( $1^{\text {st }}$ Ed.). USA: New York Rutledge and Taylor \& Francis.

Ministry of Water Resources (MoWR). (1999). Ethiopian Water Resources Management Policy. Addis Ababa: FDRE.

Ostrom, E. (2013). Do Institutions for Collective Action Evolve? Journal of Bio Econonomics. 16(1): 3-30. doi: 10.1007/s10818-013-9154-8. 
Petersen-perlman, J.D.,Veilleux, J.C., Zentner, M. and Wolf, A.T. (2012). Complexity and the Role of Institutions." Journal of Contemporary Water Research \& Education, 149:4-12.

Petit, O. and Baron, C. (2009). "Integrated Water Resources Management: From General Principles to Its Implementation by the State. The Case of Burkina Faso." Natural Resources Forum, 33(1): 49-59. DOI: 10.1111/j.1477-8949.01208.x

Reta Hailu, Degefa Tolossa and Getnet Alemu. (2017). Water security: stakeholders' arena in the Awash River Basin of Ethiopia. Sustainable. Water Resource. Management. doi: 10.1007/s40899-017-0208-2.

Reta Hailu, Degefa Tolossa and Getnet Alemu. (2018). Water institutions in the Awash basin of Ethiopia: the Discrepancies between Rhetoric and Realities, The International Journal of River Basin Management, 16 (1): 107121. doi: 10.1080/15715124.2017.1387126.

Saleth, R. M. and Dinar, A. (2004). The Institutional Economics of Water: A CrossCountry Analysis of Institutions and Performance (English). Washington, DC: World Bank.

Saleth, R.M. and Dinar, A. (2008). Linkages within Institutional Structure: An Empirical Analysis of Water Institutions. Journal of Institutional Economics, 4: 375-401. doi: 10.1017/S1744137408001136.

Saravanan, V. S., McDonald G.T., and Mollinga, P.P. (2009). Critical review of Integrated Water Resources Management: Moving beyond polarized discourse. Natural Resources Forum, 33: 76-86.

Savenije, H.H.G., Hoekstra, A.Y. (2009). "Water Resources Management" Encyclopedia of Life Support systems (ELOSS), 2: 155-180.

Shimelis, Beyene, (2012). Livelihood Diversification among the Pastoral and Agropastoral Groups in the Upper Awash Valley, Ethiopia. Journal Human Ecology, 39(3): 241-253.

Simonovic, S.P. (2008). Managing Water Resources: Methods and Tools for a Systems Approach. VODOPRIVREDA, 40:157-165.

Smith, M. and Jønch Clausen, T. (2012). Integrated Water Resource Management: A New Way Forward [A Discussion Paper of the World Water Council Task Force on IWRM, Pp.1-21]. France: Marseille.

Suhardiman, D., Clement, F., and Bharati, L. 2015. Integrated Water Resources Management in Nepal: Key Stakeholders Perceptions and Lessons Learned. International Journal of Water Resource Development. 31: 284-300.

Taddese, G., Sonder, K. and Peden, D. (2005). "The water of the Awash River basin a future challenge to Ethiopia." International Journal of Water Resource and Protection, 5(2). DOI: 10. 1080/15715124.2017.1387126 
Reta Hailu, Degefa Tolossa \& Getnet Alemu

The Global Water Partnership (GWP) and the International Network of Basin Organizations (INBO). (2009). A Handbook for Integrated Water Resources Management in Basins. Paris, France.

Van Koppen, B. and Schreiner, B. (2014). "Moving beyond integrated water resource management: developmental water management in South Africa." International Journal of Water Resource Development, 30: 1-16.

Varis, O., Enckell, K. and Keskinen, M. (2014). "Integrated water resources management: horizontal and vertical explorations and the "water in all policies approach." International Journal of Water Resource Development, 30: 433-444.

Ventana Systems, Inc. (2017). Vensim Version 7.2. USA: Harvard. Available at: http://www.vensim.com/documentation (Accessed on 29 January 2018).

Wikipedia, the free encyclopedia (undated). Non-revenue water. Retrieved from Wikipedia, the free encyclopedia. Website: https://en.wikipedia.org/wiki/Nonrevenue_water

World Health Organization (WHO) and United Nations Children's Fund (UNICEF) Joint Monitoring Program. (2014). Global Water Supply \& Sanitation Assessment Report. WHO \& UNICEF: Geneva \& New York.

WWAP \& MoWR. (2004). National Water Development Report for Ethiopia. Addis Ababa, Ethiopia.

Zinzani, A. and Bichsel, C. 2018. IWRM and the Politics of Scale: Rescaling Water Governance in Uzbekistan. Water, 10(281): 1-16. 